\title{
Dynamic CZT-SPECT in coronary artery disease: Where are we now?
}

\author{
Valeria Cantoni, PhD, ${ }^{\mathrm{a}}$ Roberta Green, $\mathrm{PhD},{ }^{\mathrm{a}}$ Adriana D'Antonio, $\mathrm{MD},{ }^{\mathrm{a}}$ and \\ Alberto Cuocolo, MD \\ a Department of Advanced Biomedical Sciences, University Federico II, Naples, Italy
}

Received Jul 9, 2021; accepted Jul 9, 2021

doi: $10.1007 / \mathrm{s} 12350-021-02752-1$

See related article, pp. 1686-1697

Myocardial perfusion imaging (MPI) with singlephoton emission computed tomography (SPECT) is an important noninvasive imaging tool for diagnosis, risk stratification and prognostic evaluation in coronary artery disease (CAD). ${ }^{1}$ SPECT MPI evaluates the presence, extent and degree of myocardial ischemia and/or infarction usually through visual observation or semiquantitative parameters. Despite its diagnostic and prognostic values, the relative nature of perfusion images may limit the ability of SPECT to identify patients with high-risk, multivessel CAD. ${ }^{2,3}$ These limitations with respect to visual or semi-quantitative assessment of regional myocardial perfusion defects can result in the underestimation or misdiagnosis of "balanced" ischemia. In patients with a balanced multivessel CAD or microcirculatory disorders a global reduction in myocardial perfusion can be completely overlooked when assessment is based solely on the relative radiotracer uptake. The underestimation of CAD extent and severity is associated with inadequate discrimination of diffuse nonobstructive and small vessel disease, due to the restrained resolution of traditional sodium-iodine systems. This eventuality can be surmounted by the quantification of myocardial blood flow (MBF) or myocardial perfusion reserve (MPR) using a tracer kinetic method for positron emission tomography (PET). ${ }^{4-7}$ PET MPI is a well-validated noninvasive method for the quantification of myocardial perfusion

Reprint requests: Valeria Cantoni, PhD, Department of Advanced Biomedical Sciences, University Federico II, Via Pansini 5, 80131 Naples, Italy; valeria.cantoni@unina.it

J Nucl Cardiol 2022;29:1698-701.

1071-3581/\$34.00

Copyright (C) 2021 American Society of Nuclear Cardiology. imaging studies, demonstrating an incremental diagnostic and prognostic power of MPR over relative perfusion imaging findings in patients with suspected or known CAD ${ }^{8,9}$ Hence, PET and fractional flow reserve (FFR) are respectively considered gold standards for noninvasive MBF and MPR quantitative measurement ${ }^{10-12}$ and invasive assessment of coronary artery stenosis severity. ${ }^{12,13}$ However, since the installation of a PET tracer production system involves high costs, this technology is not yet readily available in many areas around the world. ${ }^{14}$ The introduction of high-sensitivity dedicated cardiac cadmium-zinc-telluride (CZT) SPECT cameras, allows dynamic acquisition of tomographic images suitable for assessment of radiotracer kinetics and opens up a new era for myocardial flow and flow reserve measurement using SPECT imaging. ${ }^{15-17}$ CZTSPECT can not only achieve low-dose MPI imaging, but also provide parameters for quantitative analysis of absolute MBF through fast dynamic tomography, such as stress or rest MBF and MPR. Quantification of MBF and MPR by list-mode dynamic CZT-SPECT is technically feasible and clinically useful. ${ }^{18,19}$ Therefore, MPR is now considered a robust approach that provides incremental value on diagnosis and risk assessment of patients, including those with multivessel disease. ${ }^{20-23}$ Ben-Haim et al. ${ }^{15}$ showed that global and regional MPR by CZT-SPECT have a good correlation with total perfusion defect. Moreover, in a subgroup of patients with available angiographic data, global MPR correlated inversely with the extent of obstructive CAD. These findings were later confirmed in the WATERDAY study, ${ }^{24}$ comparing MBF and MPR from dynamic ${ }^{99 \mathrm{~m}}$ Tc-sestamibi CZT-SPECT with ${ }^{15} \mathrm{O}$-water PET and FFR. While stress and rest MBF were significantly overestimated with CZT-SPECT compared to PET, MPR was similar with the two techniques, highlighting that quantification of MBF and MPR by dynamic ${ }^{99 \mathrm{~m}} \mathrm{Tc}-$ sestamibi CZT-SPECT is technically feasible with specific correction for the extraction fraction of ${ }^{99 \mathrm{~m}} \mathrm{Tc}$ - 
sestamibi. $^{24}$ These findings support the use of this new technique to guide referrals for invasive coronary angiography or as an optional "add-on" investigation after coronary angiography/FFR when the functional severity of stenosis is uncertain or when FFR is contraindicated (i.e., sub-occluded artery). ${ }^{24}$ Acampa et al. ${ }^{25}$ demonstrated that hyperemic MBF and MPR values obtained by CZT-SPECT are higher than those measured by ${ }^{82} \mathrm{Rb}$-PET imaging, with a moderate correlation between the two methods. CZT-SPECT showed good diagnostic accuracy for the identification of obstructive CAD. Global and regional MPR were also predictive of the extent of CAD ${ }^{16}$ and agreed with the FFR measurements on invasive angiographs. ${ }^{26}$ Shirashi et al. ${ }^{14}$ reported that MPR using a CZT camera can identify balanced ischemia in patients with a left main or 3-vessel disease. In patients with suspected or known CAD a relationship between MPI findings and both hyperemic MBF and MPR obtained by CZT-SPECT was found. $^{27}$ Yet, global MPR resulted independent predictor of CAD and regional MPR was useful for the identification of obstructive CAD in the corresponding coronary artery. ${ }^{27}$ Different studies outlined the incremental value of measurements of coronary flow reserve in different categories of patients for both diagnostic and prognostic purposes. $^{22}$ Quantitative measurements of coronary vascular function can improve the diagnostic accuracy of MPI. In particular, patients with severe multivessel CAD, where a normal MPI result does not necessarily identify truly low-risk subgroups among high-risk cohorts, usually show a reduced MPR. ${ }^{16,22}$ Nkoulou et al. ${ }^{17}$ in 28 patients referred to perfusion imaging with either CZT-SPECT and PET for clinical evaluation of CAD showed an overall good correlation between ${ }^{99 \mathrm{~m}}$ Tc-tetrofosmin CZT-SPECT and ${ }^{13} \mathrm{~N}$-ammonia PET MBF values $(r=0.62, P<.001)$. However, MPR values by CZT-SPECT were lower compared to those obtained by ${ }^{13} \mathrm{~N}$-ammonia PET, probably due to higher ${ }^{13} \mathrm{~N}$-ammonia extraction fraction at resting conditions over a larger range of MBF. Nevertheless, in the clinical setting consistent disagreement may still exist between FFR values and absolute MBF and CFR, as determined by PET imaging, possibly due to the variable effects of diffuse coronary atherosclerosis and/or microvascular dysfunction on coronary hemodynamic. $^{11,12}$ The disagreement with FFR evaluation becomes even greater when traditional cardiac imaging modalities is considered, with conventional SPECT imaging showing, at best, a moderate accuracy in predicting the outputs of invasive assessment. $^{28}$ Notwithstanding the excellent diagnostic value of FFR, it quantifies the pressure gradient across the stenosis, but does not reflect microcirculation. As opposed to FFR, MPR reflects flow in epicardial arteries and microvasculature. ${ }^{29}$ It should be stressed that abnormal MPR with insignificant FFR indicates microvascular dysfunction or diffuse CAD. Therefore, FFR and MPR are not equivalent. ${ }^{28}$ Moreover, anatomical assessment does not reflect the MPR calculated with CZT-SPECT MPI. It should be noted that multiple factors can affect the hemodynamic flow response to luminal stenosis, including lesion geometry and location and the presence of collateral vessels, impacting overall regional flow. de Souza et al. ${ }^{29}$ showed that both global MPR and stress MBF were reduced in patients with abnormal perfusion results. Yoshinaga et al. ${ }^{6}$ also reported that areas with perfusion defects on ${ }^{99 \mathrm{~m}}$ Tc-tetrofosmin SPECT demonstrated lower myocardial flow reserve using PET with ${ }^{15} \mathrm{O}$-labeled water. Besides assessing perfusion, the study conducted by de Souza et al. demonstrated that global MPR is inversely associated with CAD prognostic index (CADPI), a hierarchical index that encompasses all epicardial coronary tree and is related to overall cardiovascular risk. ${ }^{29}$ Their results are in close agreement with those described by Taqueti et al. ${ }^{30}$ in a similar population of patients who underwent both PET and coronary angiography for the evaluation of known or suspected CAD.

In this scenario, in the current issue of the Journal, Panjer et al. ${ }^{31}$ conducted a systematic review and metaanalysis aimed to evaluate the diagnostic accuracy of dynamic CZT-SPECT in CAD compared to quantitative coronary angiogram (CAG), FFR and PET as reference. The authors reviewed and analyzed nine articles reported to perform dynamic CZT-SPECT and within half a year the methodological references coronary angiography with or without FFR, positron emission tomography, magnetic resonance or coronary computer tomography angiography. For the assessment of CZTSPECT the diagnostic value pooled analysis with a bivariate model was calculated and yielded a sensitivity of $0.79(95 \%$ CI $0.73-0.85)$ and a specificity of 0.85 (95\% CI 0.74-0.92). Diagnostic odds ratio (DOR) was 17.82 (95\% CI 8.80-36.08, $P<.001$ ). Positive likelihood ratio (PLR) and negative likelihood ratio (NLR) were $3.86(95 \%$ CI 2.76-5.38, $P<.001)$ and $0.21(95 \%$ CI $0.13-0.33, P<.001)$, respectively. The results of this systematic review and meta-analysis, emphasize the role of dynamic CZT-SPECT MPI with a good sensitivity and specificity to diagnose CAD as compared to the gold standards. Despite the diagnostic accuracy of CZTSPECT has already been analyzed in two previous metaanalyses, ${ }^{32,33}$ the topic is well argued and adds new appealing information to the current literature. The use of CZT-SPECT systems for the measurement of MPR is very attractive considering that in one examination is possible to obtain perfusion and functional parameters with comparable results to PET imaging. However, what 
emerges from this meta-analysis is that the protocol used in the different centers should be more standardized. The included studies use different methodologies, in terms of dose administration, acquisition protocol, CZT cameras, radiotracers and software package used for MPI CZTSPECT calculation. Furthermore, in each study a different cut-off value for dynamic SPECT MPI was set. Seven studies used as a comparator FFR (77.8\%) and two used MPI-PET (22.2\%). The definition of stenosis based on FFR was also slightly different. Three studies defined FFR $\leq 0.8(33.3 \%)$ and four FFR $<0.8(44.4 \%)$ as significant. For the measurement of MPI acquisition was performed with different types of CZT-SPECT cameras, six studies (66.7\%) used Discovery NM 530c (GE Healthcare, Chicago, IL, USA), one study (11.1\%) used Discovery NM/CT 570c (Alcyone technology, GE Healthcare, Haifa, Israel) and two studies (22.2\%) used D-SPECT (Spectrum Dynamics, Palo Alto, California). Dual isotope administration was used in one study $(11.1 \%)$, two studies $(22.2 \%)$ used ${ }^{201} \mathrm{Tl}$ as radiotracer, and six studies $(66.7 \%)$ used ${ }^{99 m}$ Tc-labeled tracers. Importantly, different software was used for the MBF quantification and measurement of MPR, including inhouse software, with Corridor 4DM (INVIA, Ann Arbor, MI, USA) applied more frequently than others. Moreover, the main limitation of this systematic review and meta-analysis, additional to the typical limitations for this kind of analysis, is a relatively small number of included studies and patients and heterogeneity within comparators. In this view, studies with a larger population and a lower variability between the methodologies, such as different thresholds for MPR, myocardial radiotracer distribution, reconstruction algorithms, and flow model applied, will be needed to demonstrate clearly the additive clinical impact of $\mathrm{MBF}$ quantitation on dynamic CZT imaging and to encourage the use of a standard approach in the quantification of MBF and MPR which is expected to become an important tool in routine clinical practice.

\section{Disclosures}

V. Cantoni, R. Green, A. D'Antonio and A. Cuocolo declare that they have no financial conflict of interest.

\section{References}

1. Al Badarin FJ, Malhotra S. Diagnosis and prognosis of coronary artery disease with SPECT and PET. Curr Cardiol Rep 2019;21:57.

2. Berman DS, Kang X, Slomka PJ. Underestimation of extent of ischemia by gated SPECT myocardial perfusion imaging in patients with left main coronary artery disease. J Nucl Cardiol 2007; 14:521-8.

3. Lima RSL, Watson DD, Goode AR, Siadaty MS, Ragosta M, Beller GA et al. Incremental value of combined perfusion and function over perfusion alone by gated SPECT myocardial perfusion imaging for detection of severe three-vessel coronary artery disease. J Am Coll Cardiol 2003;42:64-70.

4. Hara T, Michihata T, Yokoi F, Sakamoto S, Masuoka T, Iio M. Quantitative measurement of regional myocardial blood flow in patients with coronary artery disease by intravenous injection of $13 \mathrm{~N}$-ammonia in positron emission tomography. Eur J Nucl Med 1990;16:231-5.

5. Muzik O, Duvernoy C, Beanlands RS, Sawada S, Dayanikli F, Wolfe ER Jr et al. Assessment of diagnostic performance of quantitative flow measurements in normal subjects and patients with angiographically documented coronary artery disease by means of nitrogen-13 ammonia and positron emission tomography. J Am Coll Cardiol 1998;31:534-40.

6. Yoshinaga K, Katoh C, Noriyasu K, Iwado Y, Furuyama H, Ito Y et al. Reduction of coronary flow reserve in areas with and without ischemia on stress perfusion imaging in patients with coronary artery disease: A study using oxygen 15-labeled water PET. J Nucl Cardiol 2003;10:275-83.

7. Parkash R, deKemp RA, Ruddy TD, Kitsikis A, Hart R, Beauchesne $\mathrm{L}$ et al. Potential utility of rubidium 82 PET quantification in patients with 3-vessel coronary artery disease. J Nucl Cardiol 2004;11:440-9.

8. Zampella E, Acampa W, Assante R, Nappi C, Gaudieri V, Mainolfi $\mathrm{CG}$ et al. Combined evaluation of regional coronary artery calcium and myocardial perfusion by (82)Rb PET/CT in the identification of obstructive coronary artery disease. Eur J Nucl Med Mol Imaging 2018;45:521-9.

9. Assante R, Acampa W, Zampella E, Arumugam P, Nappi C, Gaudieri V et al. Prognostic value of atherosclerotic burden and coronary vascular function in patients with suspected coronary artery disease. Eur J Nucl Med Mol Imaging 2017;44:2290-8.

10. Iida H, Yokoyama I, Agostini D, Banno T, Kato T, Ito K et al. Quantitative assessment of regional myocardial blood flow using oxygen-15-labelled water and positron emission tomography: A multicentre evaluation in Japan. Eur J Nucl Med 2000;27:192201

11. Johnson NP, Gould KL, Di Carli MF, Taqueti VR. Invasive FFR and noninvasive CFR in the evaluation of ischemia: What is the future? J Am Coll Cardiol 2016;67:2772-88.

12. Danad I, Uusitalo V, Kero T, Saraste A, Raijmakers PG, Lammertsma AA et al. Quantitative assessment of myocardial perfusion in the detection of significant coronary artery disease: Cutoff values and diagnostic accuracy of quantitative O-15 H2O PET imaging. J Am Coll Cardiol 2014;64:1464-75.

13. Kajander SA, Joutsiniemi E, Saraste M, Pietilä M, Ukkonen H, Saraste A et al. Clinical value of absolute quantification of myocardial perfusion with (15) O-water in coronary artery disease. Circ Cardiovasc Imaging 2001;4:678-84.

14. Shiraishi S, Tsuda N, Sakamoto F, Ogasawara K, Tomiguchi S, Tsujita K et al. Clinical usefulness of quantification of myocardial blood flow and flow reserve using CZT-SPECT for detecting coronary artery disease in patients with normal stress perfusion imaging. J Cardiol 2020;75:400-9.

15. Ben-Haim S, Murthy VL, Breault C, Allie R, Sitek A, Roth N et al. Quantification of myocardial perfusion reserve using dynamic SPECT imaging in humans: A feasibility study. J Nucl Med 2013;54:873-9.

16. Ben Bouallègue F, Roubille F, Lattuca B, Cung TT, Macia JC, Gervasoni $\mathrm{R}$ et al. SPECT myocardial perfusion reserve in patients with multivessel coronary disease: Correlation with angiographic findings and invasive fractional flow reserve measurements. J Nucl Med 2015;56:1712-27. 
17. Nkoulou R, Fuchs TA, Pazhenkottil AP, Kuest SM, Ghadri JR, Stehli $\mathrm{J}$ et al. Absolute myocardial blood flow and flow reserve assessed by gated SPECT with cadmium-zinc-telluride detectors using 99mTc-Tetrofosmin: Head-to-head comparison with 13Nammonia PET. J Nucl Med 2016;57:1887-92.

18. Esteves FP, Raggi P, Folks RD, Keidar Z, Wells Askew J, Rispler $\mathrm{S}$ et al. Novel solid-state-detector dedicated cardiac camera for fast myocardial perfusion imaging: Multicenter comparison with standard dual detector cameras. J Nucl Cardiol 2009;16:927-34.

19. Bocher M, Blevis IM, Tsukerman L, Shrem Y, Kovalski G, Volokh L. A fast cardiac gamma camera with dynamic SPECT capabilities: Design, system validation and future potential. Eur J Nucl Med Mol Imaging 2010;37:1887-902.

20. Lortie M, Beanlands RSB, Yoshinaga K, Klein R, DaSilva JN, DeKemp RA. Quantification of myocardial blood flow with 82Rb dynamic PET imaging. Eur $\mathrm{J}$ Nucl Med Mol Imaging 2007;34:1765-74.

21. Ziadi MC, DeKemp RA, Williams K, Guo A, Renaud JM, Chow BJW et al. Does quantification of myocardial flow reserve using rubidium-82 positron emission tomography facilitate detection of multivessel coronary artery disease? J Nucl Cardiol 2012;19:67080.

22. Murthy VL, Naya M, Foster CR, Hainer J, Gaber M, Di Carli G et al. Improved cardiac risk assessment with noninvasive measures of coronary flow reserve. Circulation 2011;124:2215-24.

23. Naya M, Murthy VL, Taqueti VR, Foster CR, Klein J, Garber M et al. Preserved coronary flow reserve effectively excludes high risk coronary artery disease on angiography. J Nucl Med 2014;55:248-55.

24. Agostini D, Roule V, Nganoa C, Roth N, Baavour R, Parienti JJ et al. First validation of myocardial flow reserve assessed by dynamic 99mTc-sestamibi CZT-SPECT camera: Head-to-head comparison with 15O-water PET and fractional flow reserve in patients with suspected coronary artery disease. The WATERDAY study. Eur J Nucl Med Mol Imaging 2018;45:1079-90.

25. Acampa W, Zampella E, Assante R, Genova A, De Simini G, Mannarino $T$ et al. Quantification of myocardial perfusion reserve by CZT-SPECT: A head to head comparison with 82Rubidium PET imaging. J Nucl Cardiol 2020. https://doi.org/10.1007/s1235 0-020-02129-w.
26. Miyagawa M, Nishiyama Y, Uetani T, Ogimoto A, Ikeda S, Ishimura $\mathrm{H}$ et al. Estimation of myocardial flow reserve utilizing an ultrafast cardiac SPECT: Comparison with coronary angiography, fractional flow reserve, and the SYNTAX score. Int J Cardiol 2017;244:347-53.

27. Acampa W, Assante R, Mannarino T, Zampella E, D'Antonio A, Buongiorno $\mathrm{P}$ et al. Low-dose dynamic myocardial perfusion imaging by CZT-SPECT in the identification of obstructive coronary artery disease. Eur $\mathrm{J}$ Nucl Med Mol Imaging 20210;47:1705-12.

28. Zavadovsky KV, Mochula AV, Boshchenko AA, Vrublevsky AV, Baev AE, Krylov AL et al. Absolute myocardial blood flows derived by dynamic CZT scan vs invasive fractional flow reserve: Correlation and accuracy. J Nucl Cardiol 2021;28:249-59.

29. de Souza ACDAH, Gonçalves BKD, Tedeschi AL, Lima RSL. Quantification of myocardial flow reserve using a gamma camera with solid-state cadmium-zinc-telluride detectors: Relation to angiographic coronary artery disease. J Nucl Cardiol 2021;28:876-84.

30. Taqueti VR, Hachamovitch R, Murthy VL, Naya M, Foster CR, Hainer $\mathbf{J}$ et al. Global coronary flow reserve is associated with adverse cardiovascular events independently of luminal angiographic severity and modifies the effect of early revascularization. Circulation 2015;131:19-27.

31. Panjer M, Dobrolinska M, Wagenaar NRL, Slart RHJA. Diagnostic accuracy of dynamic CZT-SPECT in coronary artery disease. A systematic review and meta-analysis. J Nucl Cardiol 2021. https://doi.org/10.1007/s12350-021-02721-8.

32. Cantoni V, Green R, Acampa W, Zampella E, Assante R, Nappi C et al. Diagnostic performance of myocardial perfusion imaging with conventional and CZT single-photon emission computed tomography in detecting coronary artery disease: A meta-analysis. J Nucl Cardiol 2021;28:698-715.

33. Zhang YQ, Jiang YF, Hong L, Chen M, Zhang NN, Yang HJ et al. Diagnostic value of cadmium-zinc-telluride myocardial perfusion imaging versus coronary angiography in coronary artery disease: A PRISMA-compliant meta-analysis. Medicine 2019;98:e14716.

Publisher's Note Springer Nature remains neutral with regard to jurisdictional claims in published maps and institutional affiliations. 